\title{
Reexamination of reflexive arterial catheter placement in ICU patients
}

\author{
David Sheely MSCS, Hawa Edriss MD
}

$\boldsymbol{R}$ ecent studies by Gershengorn and Garland suggest that approximately one-third of ICU patients $(\sim 2,000,000)$ in the United States, perhaps more in Canada, have an arterial catheter (AC) during their ICU stay, with replacements and reinsertions increasing the total number. ${ }^{1,2}$ The rationale is based on wellintended goals to facilitate diagnostic phlebotomy, augment hemodynamic monitoring, and monitor arterial blood gases. However, given this usage pattern, it would be reasonable to consider whether or not AC placement reduces mortality.

Complications occur in less than $1 \%$ of $A C$ placements, but these catheters are associated with temporary vascular occlusion, local infection, sepsis, pseudoaneurysm formation, hematomas, and bleeding. ${ }^{3}$ Arterial catheters are also associated with excessive testing and phlebotomy, which can lead to anemia and consequent blood transfusion. ${ }^{2} \mathrm{~A}$ common justification for use of ACs is that invasive blood pressure monitoring has higher fidelity than noninvasive measurements. Garland notes, however, that both methods are prone to inaccuracies, and that a study by Lakhal et al found automated noninvasive blood pressure measurements identified hypotension, defined as AC-derived mean arterial pressure < $65 \mathrm{mmHg}$, with a sensitivity and specificity of $95 \%{ }^{2.4}$ A retrospective database collected between 2001 and 2007 on 27,022 simultaneously recorded invasive arterial blood pressure and noninvasive blood pressure pair measurements showed significant discrepancies between invasive and noninvasive oscillometric methods in measuring systolic blood pressure during hypotension. ${ }^{5}$ However, the mean arterial pressures were similar. Additionally, it was noted that non-invasive blood pressure measurements tended to underestimate systolic blood pressures in patients with hypertension and overestimate systolic pressures in patients with hypotension when compared to invasive blood pressure readings. There were no significant differences between hypotensive $(\leq 60 \mathrm{mmHg})$ invasive and noninvasive mean arterial pressure readings with respect to ICU mortality and acute kidney injury prevalence.

A propensity-matched cohort analysis of data in the Project IMPACT database $(2001-2008)$ identified 13,603 propensity score matched pairs of patients in the ICU who required mechanical ventilation, one with and one without an AC. Analysis indicated that $A C$ use was not associated with reduced hospital mortality. ${ }^{1}$ Garland notes that in the same study among nearly 11,000 patients needing vasopressors for shock, mortality was higher in patients who had an AC (OR, 1.08; $\mathrm{P}=0.008){ }^{2}$ Hsu analyzed patients admitted to the Beth Israel Deaconess Medical Center ICU and intubated within 24 hours of admission and found no association between the placement of an AC and 28-day mortality. Placement of an AC was, however, associated with longer mechanical ventilation support, longer ICU and hospital lengths of stay, and more frequent blood gas measurements.

These studies appear to make a compelling argument that there is no evidence that AC use improves outcomes in ICU patients on mechanical ventilation but does increase costs (the set-up charge is $\$ 437$ in our hospital). Against this backdrop, however, intensivists trained in centers with routine AC use often never critically question the idea that critically ill patients require ACs. ${ }^{2}$ Given this, it could be uncomfortable for the traditionalists and dataphiles among us to contemplate forgoing AC placement, but it would be logical to reconsider this reflex and to call for large randomized controlled trials to help clarify the current clinical equipoise. Might we see a change in practice similar to that which followed the randomized trials in- 
dicating that the use of pulmonary arterial catheters did not improve clinically relevant outcomes?

Author Affiliation: David Sheely is a medical student at Texas Tech University Health Sciences Center in Lubbock, TX. Hawa Edriss is a fellow in Pulmonary and Critical Care Medicine at TTUHSC in Lubbock, TX.

Received: 03/19/2016

Accepted: 04/03/2016

Published electronically: 04/15/2016

Conflict of Interest Disclosures: none Corresponding Author: David Sheely MSCS

Contact Information: : David.sheely@ttuhsc.edu

DOI: $10.12746 /$ swrccc2016.0414.181

\section{REFERENCES}

1. Gershengorn HB, Wunsch H, Scales DC, et al. Association between arterial catheter use and hospital mortality in intensive care units. JAMA Intern Med 2014:174(11):1746-1754.doi:100.1001/ jamainternmed.2014.3297, Published online September 8, 2014. 2. Garland A. Arterial Lines in the ICU - A call for rigorous controlled trials. CHEST 2014; 146(5):1155-1158.

3. Scheer BV, Perel A, Pfeiffer UJ. Clinical review: Complications and risk factors of peripheral arterial catheters used for hemodynamic monitoring in anaesthesia and intensive care medicine. Crit Care 2002; 6(3): 199-204, Published online 2002 Apr 18.

4. Lakhal K, Macq C, Ehrmann S, et al. Noninvasive monitoring of blood pressure in the critically ill: reliability according to the cuff site (arm, thigh, or ankle). Crit Care Med 2012; 40(4):12071213.

5. Lehman LH, Saeed M, Talmor D, Mark R, et al. Methods of blood pressure measurement in the ICU. Crit Care Med. 2013 Jan; 41(1): 34-40. doi: 10.1097/CCM.0b013e318265ea46

6. Hsu DJ, Mengling F, Kothari R, et al. The association between indwelling arterial catheters and mortality in hemodynamically stable patients with respiratory failure -a propensity score analysis. CHEST 2015; 148(6):1470-1476. 